\title{
A GESTÃO DEMOCRÁTICA E A MATERIALIZAÇÃO DA META 6 DO PLANO NACIONAL DE EDUCAÇÃO: POSSIBILIDADE DE EDUCAÇÃO EM TEMPO INTEGRAL NA REGIÃO METROPOLITANA DO ESTADO DO RIO DE JANEIRO
}

\author{
LA GESTIÓN DEMOCRÁTICA Y LA MATERIALIZACIÓN DE LA META 6 DEL \\ PLAN NACIONAL DE EDUCACIÓN: POSIBILIDAD DE EDUCACIÓN A TIEMPO \\ COMPLETO EN LA REGIÓN METROPOLITANA DEL ESTADO DE RÍO DE \\ JANEIRO
}

THE DEMOCRATIC MANAGEMENT AND MATERIALIZATION OF GOAL 6 OF THE NATIONAL EDUCATION PLAN: THE POSSIBILITY OF FULL-TIME EDUCATION IN THE METROPOLITAN REGION OF THE STATE OF RIO DE JANEIRO

RESUMO: O artigo visa apresentar reflexões realizadas acerca da Educação Integral e(m) Tempo Integral no panorama da meta 6 do atual Plano Nacional de Educação (PNE 20142024), na perspectiva de colaborar para a discussão sobre a ampliação da jornada escolar dos educandos e a busca por uma formação humana mais completa aos sujeitos desse processo (COELHO, 2009). A temática surgiu com a investigação realizada sobre os Centros Integrados de Educação Pública no Estado do Rio de Janeiro, criados pela Secretaria Extraordinária de Educação, na década de 80 (RIBEIRO, 1986), dinamizados pelo Programa Especial de Educação. A trajetória deste estudo passou pela Constituição Federal (CF/1988) e pela Lei de Diretrizes e Bases da Educação Nacional (LDBEN 9.394/1996), que abordam a formação integral dos sujeitos e a possibilidade do tempo ampliado. Foi realizada a análise do Programa Mais Educação (BRASIL, 2007), criado pela portaria interministerial n ${ }^{\circ} .17 / 2007$ e normatizado pelo Decreto 7.083/10. Concomitante a esta análise, buscamos entender a meta 6 do Plano Nacional de Educação (PNE/2014) e analisar a sua materialização no chão das escolas, após a chegada do Programa Novo Mais Educação de 2016. No que tange à Gestão Democrática, pretendemos investigar como a implementação da meta 19 do PNE pode possibilitar a oferta de Educação em Tempo Integral. No presente artigo, um recorte regional foi utilizado para se avançar nas discussões: a Região Metropolitana do Estado do Rio de Janeiro.

PALAVRAS-CHAVE: Plano nacional de educação. Educação integral e(m) tempo integral. CIEP. Programa novo mais educação. Gestão democrática.

RESUMEN: El artículo busca presentar reflexiones realizadas acerca de la Educación Integral y Escuelas de Tiempo Completo en el panorama de la meta 6 del actual Plan

\footnotetext{
${ }^{1}$ Universidade do Estado do Rio de Janeiro (UERJ), Rio de Janeiro - RJ - Brasil. Professora do Ensino Fundamental da Prefeitura Municipal de Duque de Caxias; Integrante do Núcleo de Estudos - Tempos, Espaços e Educação Integral (NEEPHI - UNIRIO). Pesquisadora do Grupo de Estudos, Pesquisa e Extensão Fora da Sala de Aula: formações, representações e práticas educativas não escolares. (UERJ-FFP/ São Gonçalo). DOI: <http://orcid.org/0000-0001-9471-2137>. E-mail: patriciamotauerjffp@ hotmail.com
} 
Nacional de Educación (PNE 2014-2024), en la perspectiva de colaborar para la discusión sobre la ampliación de la jornada escolar de los alumnos y la búsqueda de una formación humana más completa a los sujetos de ese proceso (COELHO, 2009). La temática surgió con la investigación realizada sobre los Centros Integrados de Educación Pública en el Estado de Río de Janeiro, creados por la Secretaría Extraordinaria de Educación, en la década de 80 (RIBEIRO, 1986), dinamizados por el Programa Especial de Educación. La trayectoria de este estudio pasó por la Constitución Federal (CF / 1988) y por la Ley de Directrices y Bases de la Educación Nacional (LDBEN 9.394 / 1996), que abordan la formación integral de los sujetos y la posibilidad del tiempo completo. Se realizó el análisis del Programa Más Educación (BRASIL, 2007), creado por la ordenanza interministerial no. 17/2007 y normatizado por el Decreto 7.083 / 10. Con respecto a este análisis, buscamos entender la meta 6 del Plan Nacional de Educación (PNE / 2014) y analizar su materialización en las escuelas, después de la llegada del Programa Novo Más Educación de 2016. En lo que se refiere a la Gestión Democrática, pretendemos investigar como la implementación de la meta 19 del PNE puede posibilitar la oferta de Educación en Tiempo Integral. En el presente artículo, un recorte regional se utilizó para avanzar en las discusiones: la Región Metropolitana del Estado de Río de Janeiro.

PALABRAS CLAVE: Plan nacional de educación. Educación integral y Escuelas de tiempo completo. CIEP. Programa nuevo Más educación. Gestión democrática.

ABSTRACT: The article aims to present reflections on Integral Education and Integral Time in the panorama of goal 6 of the current National Education Plan (PNE 2014-2024), with the perspective of collaborating in the discussion about the expansion of the school day of the and the search for a more complete human formation to the subjects of this process (COELHO, 2009). The theme arose from the research carried out on the Integrated Centers of Public Education in the State of Rio de Janeiro, created by the Extraordinary Secretariat of Education in the 1980s (RIBEIRO, 1986), promoted by the Special Education Program. The trajectory of this study was passed by the Federal Constitution (CF / 1988) and by the Law of Guidelines and Bases of National Education (LDBEN 9.394 / 1996), which deal with the integral formation of subjects and the possibility of extended time. The analysis of the More Education Program (BRASIL, 2007), created by the interministerial ordinance no. 17/2007 and regulated by Decree 7.083 / 10. Concomitant to this analysis, we sought to understand the 6th National Education Plan (PNE / 2014) and analyze its materialization on the floor of schools, after the arrival of the New Education Program in 2016. With regard to Democratic Management, we intend to investigate as the implementation of the PNE goal 19 can make it possible to offer Full Time Education. In the present article, a regional clipping was used to advance the discussions: the Metropolitan Region of the State of Rio de Janeiro.

KEYWORDS: National education plan. Integral education and integral time. CIEP. New more education program. Democratic management.

\section{Introdução}

Num contexto de retrocessos na Educação deste país, mas com a perspectiva de cumprimento das metas do Plano Nacional de Educação (BRASIL, 2014), insistimos em 
investigações que tragam, à discussão, como a meta 6 pode se materializar no chão da escola tendo em vista a oferta do tempo integral, conforme orienta o referido plano. Este interesse surgiu por ocasião do ingresso no Mestrado em Educação oferecido pela UERJ, sob orientação da Profa. Dra. Lúcia Velloso Maurício, com uma pesquisa que se debruçou sobre os movimentos de uma escola em busca de uma educação integral em tempo integral, localizada na rede municipal de Duque de Caxias.

Após 10 anos trabalhando em um Centro Integrado de Educação Pública (CIEP), venho refletindo sobre o Programa Especial de Educação (PEE), que instituiu os CIEPs no estado do Rio de Janeiro; sobre os movimentos de ampliação da jornada que aconteceram neste espaço, após o desmonte do PEE; e também sobre as políticas públicas que chegaram no chão da escola para aumentar o tempo de estudos dos estudantes. Percebemos, nesta jornada que, após o término do PEE, na década de 90, uma gestão democrática, eleita à época, possibilitou a chegada, na Unidade Escolar, de projetos e atividades que ampliaram a permanência dos alunos. Neste sentido, é possível que uma educação integral e(m) tempo integral se efetive mediante a existência de uma gestão democrática nas escolas.

Durante a pesquisa, com a participação no Núcleo de Estudos - Tempos, Espaços e Educação Integral (NEEPHI - UNIRIO), grupo de pesquisa que existe há mais de 20 anos dialogando acerca desta temática, produzimos um texto publicado no blog do grupo de pesquisa e artigos aceitos para publicação no Dossiê Temático sobre Darcy Ribeiro da Revista Artes de Educar e nos anais do XIII EDUCERE, IV SIRSSE, VI SIPD - Cátedra UNESCO, no eixo 18 - Políticas Públicas e Gestão da Educação/ PUCPR-2017. Com o objetivo de avançar nesta discussão, participamos, em julho deste ano, do "II Seminário de Educação Integral: concepções e práticas no Brasil/UNICAMP”, e apresentamos comunicação oral, tendo em vista a possibilidade de dialogar com pesquisadores, professores e outros sujeitos que vivenciam e/ou estudam o assunto.

Como pesquisadores do Grupo de Estudos, Pesquisa e Extensão Fora da Sala de Aula: formações, representações e práticas educativas não escolares (UERJ-FFP/ São Gonçalo), estudamos as possibilidades de ampliação da jornada em contextos escolares e não-escolares e como a gestão democrática pode mediar e favorecer estes processos, sobretudo, no atual panorama de retrocessos que vivenciamos na educação brasileira, devido à instabilidade política e econômica.

Sendo assim, no bojo das políticas públicas, à luz das teorias, das pesquisas, da legislação e com a análise dos resultados obtidos na pesquisa, é possível inferir que há, em alguns contextos, um esforço por abraçar políticas e projetos que propiciem o aumento da 
permanência das crianças na escola, sempre com a mediação da direção. Neste sentido, pretendo verificar se, nos municípios da Região Metropolitana do Estado do Rio de Janeiro, uma gestão democrática viabiliza a ampliação da jornada e a oferta de oportunidades educativas que colaborem para a formação mais completa possível dos sujeitos (COELHO, 2009). Entendemos, portanto, que este seria o papel da escola na construção do conhecimento.

A Professora Doutora Elisângela da Silva Bernardo, que atua no campo das Políticas públicas e Gestão da Educação, inserido na linha de pesquisa "Políticas e práticas em educação" da UNIRIO, contribui com este estudo, uma vez que investiga políticas, programas e práticas de gestão da educação e da educação em tempo integral. O tema escolhido "A gestão democrática e a materialização da meta 6 do Plano Nacional de Educação: possibilidade de educação em tempo integral na região metropolitana do estado do Rio de Janeiro" se justifica pela necessidade de se analisar em que medida uma gestão democrática favorece a ampliação do tempo de permanência dos estudantes nas Unidades Escolares numa perspectiva de educação integral e(m) tempo integral. Conhecer e divulgar estas experiências é de grande relevância.

Segundo Amaral (2016, p. 83), “a escolha para diretor nas escolas sempre foi um assunto muito polêmico e discutido tanto nas redes quanto entre especialistas da educação". E, possivelmente, esta escolha pode (im)possibilitar o avanço de políticas que visam ao aumento da jornada.

$\mathrm{Na}$ nomeação ou indicação, o diretor é escolhido pelo chefe do Poder Executivo, estando a direção no mesmo esquema dos denominados "cargos de confiança". Nessa condição, o diretor pode ser substituído a qualquer tempo, de acordo com o momento político e as conveniências. (AMARAL, 2016, p. 84)

Neste bojo, a continuidade das políticas públicas pode ser comprometida, sobretudo se a participação, um dos pilares da gestão democrática, não se efetivar nas práticas educativas nas instituições de ensino. Esta investigação se propõe a buscar resultados que levem a uma reflexão sobre a gestão democrática, no âmbito da meta 19 do PNE (BRASIL, 2014) e sobre as políticas que tratam do tempo integral e de uma educação de qualidade que favoreça a “educação integral. Mas, educação integral, "como conceito em construção" (CAVALIERE, 2015), é uma investigação que demandará mais tempo ainda, pois se trata de definir e mensurar o que forma integralmente os sujeitos. No entanto, sugerimos que, trabalhar numa perspectiva da educação integral, talvez seja oferecer aos estudantes o maior acesso possível a atividades diferenciadas e a um currículo construído sócio historicamente pelas escolas, 
trabalhado com qualidade e de forma significativa para os sujeitos. Num tempo ampliado, haveria mais chances de que isto ocorresse.

\section{Objetivos}

O objetivo geral deste estudo em andamento é, portanto, identificar em que medida a gestão democrática viabiliza a implementação de políticas de tempo integral. Trago como justificativa deste problema, a necessidade de uma reflexão sobre como a gestão pode (im)possibilitar a implementação de políticas públicas, nos contextos escolares, sobretudo aquelas voltadas para oferta de educação em tempo integral na região metropolitana do estado do Rio de Janeiro.

Serão observados os seguintes objetivos específicos:

a) Caracterizar o processo histórico da política de ampliação da jornada no contexto das políticas públicas no Brasil e nos municípios da região supracitada; b) Identificar as configurações da gestão escolar e como é definida no PME de cada município; c) Verificar como as políticas que tratam do tempo integral se materializam nas escolas; d) Analisar como a gestão escolar influencia no fomento de políticas públicas de ampliação de jornada ou oferta de tempo integral.

\section{Abordagem Teórico-Metodológica}

Pensar questões relacionadas à educação integral e(m) tempo integral no Brasil nos remete ao tempo e a qualidade do ensino. A Lei de Diretrizes e Bases da Educação Nacional (BRASIL,1996) aborda, nos artigos 34 e 87, o aumento progressivo da jornada escolar e a perspectiva de uma educação em tempo integral, respectivamente. O Estatuto da Criança e do Adolescente (BRASIL, 1990), cita a importância da formação integral da criança e do adolescente e a necessidade de proteção dos mesmos. O Fundo de Manutenção e Desenvolvimento da Educação Básica e de Valorização dos Profissionais da Educação (BRASIL, 2007) concede um maior aporte de recursos à educação em tempo integral.

A Meta 6 do Plano Nacional de Educação, lei 13.005 (BRASIL, 2014), sancionado pela Presidenta Dilma Roussef, no dia 25 de junho de 2014, sugere 9 estratégias para que se ofereça educação em tempo integral em $50 \%$ das escolas públicas para $25 \%$ dos alunos da educação básica. A legislação, portanto, tem apontado para a ampliação da jornada e o Programa Mais 
Educação (BRASIL, 2007) foi uma política voltada para induzir, com alguma dificuldade, este processo.

Neste sentido, Cavaliere discute as possibilidades de educação integral e(m) tempo integral, destacando que seriam de dois tipos:

No primeiro, a ênfase estaria no fortalecimento da Unidade Escolar, com mudanças em seu interior pela atribuição de novas tarefas, mais equipamentos e profissionais com formação diversificada pretendendo propiciar a alunos e professores uma vivência institucional de outra ordem. No segundo, a ênfase estaria na oferta de atividades diversificadas aos alunos no turno alternativo ao da escola, fruto da articulação com instituições multissetoriais, utilizando espaços e agentes que não os da própria escola, pretendendo propiciar experiências múltiplas e não padronizadas (CAVALIERE, 2009, p. 53)

O Programa Mais Educação foi organizado de acordo com a segunda concepção. Por meio de parcerias, alguns alunos inscritos no programa, em cada escola, teriam acesso a atividades diversificadas no contraturno da escola. Neste modelo, temos alunos em tempo integral, enquanto, no primeiro modelo, escolas em tempo integral, como infere a autora.

Os Planos Municipais de Educação da região metropolitana do estado do Rio de Janeiro, por sua vez, apontaram o Programa Mais Educação como principal indutor dessa política.

Tabela 1: Planos Municipais de Educação dos municípios da região metropolitana do estado do Rio de Janeiro

\begin{tabular}{|c|c|c|c|c|c|}
\hline & MUNICÍPIO & LEI $N^{O}$ & $\begin{array}{lr}\text { DATA } & \text { DE } \\
\text { APROVAÇÃO DA LEI }\end{array}$ & PERÍODO & $\begin{array}{l}\text { DURAÇÃO } \\
\text { EM ANOS }\end{array}$ \\
\hline 1 & Belford Roxo & 1.529 & 24 de junho de 2015 & 2015 a 2025 & 10 \\
\hline 2 & Cachoeiras de Macacu & 2.056 & 24 de junho de 2015 & 2015 a 2025 & 10 \\
\hline 3 & Duque de Caxias & 2.713 & 30 de junho de 2015 & 2015 a 2025 & 10 \\
\hline 4 & Guapimirim & 859 & 30 de junho de 2015 & 2015 a 2025 & 10 \\
\hline 5 & Itaboraí & 2.556 & 22 de junho de 2015 & 2015 a 2025 & 10 \\
\hline 6 & Itaguaí & 3.324 & 30 de junho de 2015 & 2015 a 2025 & 10 \\
\hline 7 & Japeri & 1.301 & 23 de junho de 2015 & 2015 a 2025 & 10 \\
\hline 8 & Magé & 2.267 & 16 de junho de 2015 & 2015 a 2025 & 10 \\
\hline 9 & Maricá & 2.613 & 17 de setembro de 2015 & 2015 a 2025 & 10 \\
\hline 10 & Mesquita & 908 & 29 de junho de 2015 & 2015 a 2025 & 10 \\
\hline 11 & Nilópolis & 6.490 & 03 de setembro de 2015 & 2015 a 2025 & 10 \\
\hline 12 & Niterói & 2.610 & 31 de outubro de $2008^{*}$ & 2008 a 2018 & 10 \\
\hline 13 & Nova Iguaçu & 4.504 & 23 de junho de 2015 & 2015 a 2025 & 10 \\
\hline 14 & Paracambi & 1.169 & 18 de junho de 2015 & 2015 a 2025 & 10 \\
\hline 15 & Queimados & 1.251 & 15 de julho de 2015 & 2015 a 2025 & 10 \\
\hline 16 & Rio Bonito & 2.070 & 23 de junho de 2015 & 2015 a 2025 & 10 \\
\hline 17 & Rio de Janeiro & 4.866 & 2 de julho de $2008 *$ & 2008 a 2018 & 10 \\
\hline 18 & São Gonçalo & 658 & 09 de dezembro de 2015 & 2015 a 2025 & 10 \\
\hline 19 & São João de Meriti & 2.004 & 17 de junho de 2015 & 2015 a 2025 & 10 \\
\hline 20 & Seropédica & 566 & 01 de julho de 2015 & 2015 a 2025 & 10 \\
\hline 21 & Tanguá & 971 & 24 de junho de 2015 & 2015 a 2025 & 10 \\
\hline
\end{tabular}

Fonte: Dados organizados pela autora com base nas informações do MPRJ

*Municípios que ainda não adequaram seus Planos Municipais ao Plano Nacional de Educação. 
Convém destacar que o programa foi substituído. Em 10 de outubro de 2016, o MEC, por meio da portaria 1.144 instituiu o Programa Novo Mais Educação (BRASIL, 2016a.). E logo na apresentação do programa, no “documento orientador” (BRASIL, 2016b), consta a ênfase atribuída ao pleno domínio da leitura, da escrita e do cálculo. As escolas, por sua vez, escolhem, no momento da adesão, se oferecerão 5 ou 15 horas semanais de atividades, no seu plano de atendimento. Dispostas da seguinte maneira:

- Em 5 horas de atividades: 2 de Acompanhamento Pedagógico (1 de Língua Portuguesa e 1 de Matemática), com 2h30 de duração cada uma.

- Em 15 horas de atividades: 2 de Acompanhamento Pedagógico (1 de Língua Portuguesa e 1 de Matemática), com 4 horas de duração cada; e outras 3 atividades, a serem realizadas nas 7 horas restantes (Atividades Complementares do Campo Artes, Cultura, Esporte e Lazer).

O documento orientador divide ainda os atores que fomentarão este programa, da seguinte maneira:

- O articulador da escola: Profissional de 20 horas semanais lotado na escola. Possivelmente, os professores desenvolvam essa função.

- O mediador da aprendizagem: Responsável pelas atividades de acompanhamento pedagógico, trabalhando de forma articulada com os professores de Português e Matemática.

- O facilitador: Dinamizará as 7 horas semanais de atividades de escolha da escola. Caso a escola escolha 15 horas semanais de atividades. Neste caso, são 4 horas para Português, 4 horas para Matemática e 7 horas para 3 atividades que a escola terá liberdade para escolher. O Facilitador atuará nestas 3 atividades. Seriam aproximadamente 2 horas para cada atividade. Se a escola optar por 5 horas de atividades, o Facilitador não atuaria na Unidade Escolar, pois esta contaria apenas com 5 horas de Acompanhamento Pedagógico: duas horas e meia para Português e duas horas e meia para Matemática.

O Caderno de Orientações Pedagógicas (BRASIL, 2017) trouxe algumas questões que mostram mais detalhes acerca do referido programa. Este material ratifica a ênfase no acompanhamento pedagógico, como é possível perceber na assertiva a seguir:

No Programa Novo Mais Educação, o acompanhamento pedagógico dos estudantes ganha centralidade como estratégia para enfrentamento das dificuldades de aprendizagem e superação do fracasso escolar. Por isso, as ações propostas visam a melhoria da aprendizagem em Matemática e Língua 
Portuguesa, por meio da intervenção direta sobre o processo de alfabetização e letramento nessas duas áreas. (BRASIL, 2017, p. 20-21)

Para garantir a consecução deste objetivo, o Caderno disponibiliza uma lista de materiais que podem favorecer a formação dos sujeitos que atuarão no PNME:

Tabela 2: Materiais sugeridos para formação dos Articuladores e Mediadores do Acompanhamento Pedagógico

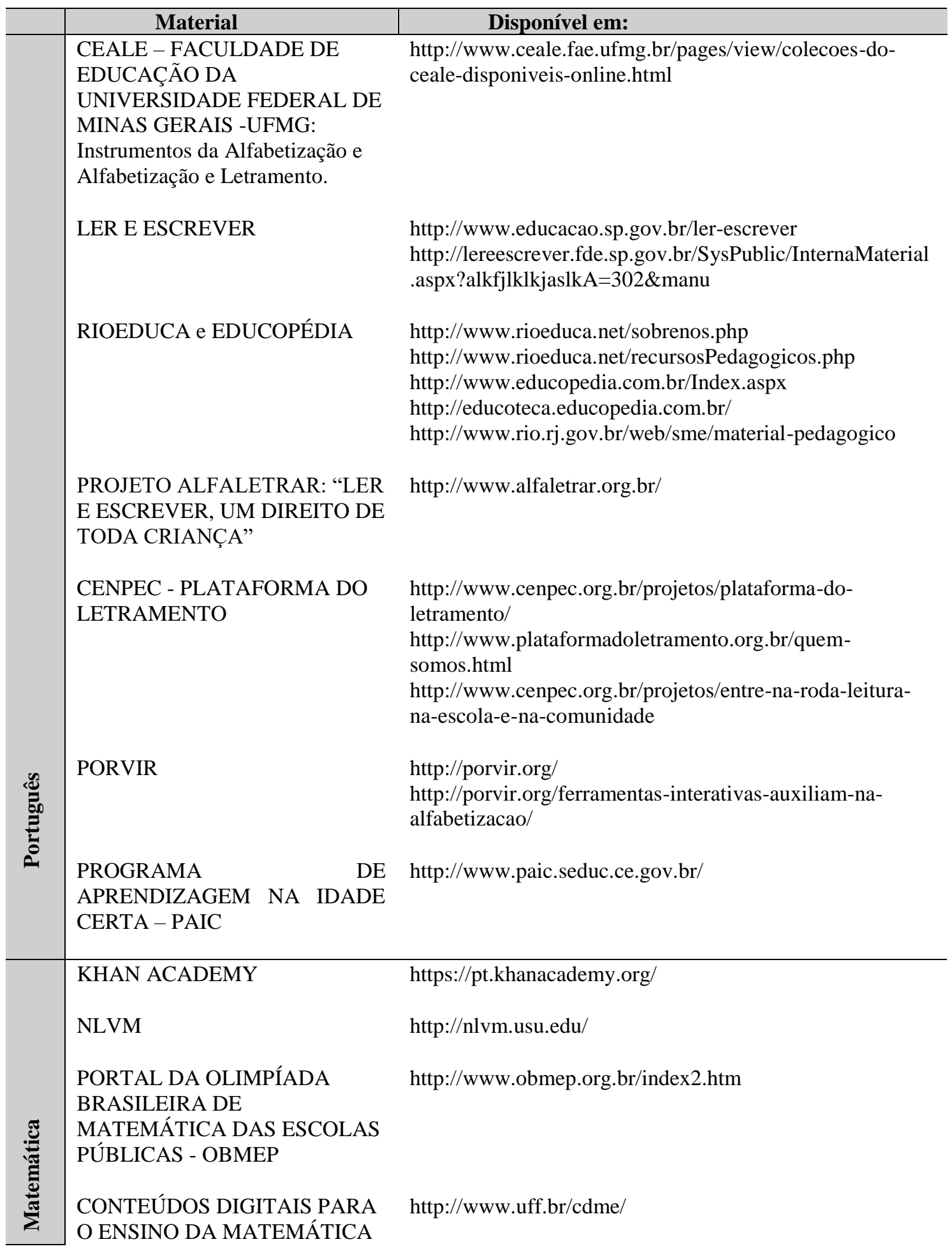


E ESTATÍSTICA DA

UNIVERSIDADE FEDERAL

FLUMINENSE - UFF

MATEMÁTICA MULTIMÍDIA http://m3.ime.unicamp.br/

DIA-A-DIA - Paraná http://www.matematica.seed.pr.gov.br/

Fonte: Dados organizados pela autora com base em informações do Caderno de Orientações Pedagógicas (BRASIL, 2017)

Em alguns trechos do documento, encontramos o termo Educação Integral para tratar desta política, no entanto, se considerarmos educação integral como a possibilidade de formação mais completa dos sujeitos, questionamos a viabilidade desta proposta, tendo em vista a valorização de dois campos do conhecimento, com oferta de material específico para eles. Por conseguinte, os demais saberes, ocupam outros lugares deste projeto, com uma carga horária diferenciada, como foi visto, anteriormente.

O documento também define os grupos de estudantes que podem participar do programa:

I. em situação de risco e vulnerabilidade social;

II. em distorção idade/ano;

III. com alfabetização incompleta;

IV. repetentes;

V. com lacunas de aprendizagem em Língua Portuguesa e Matemática; VI. em situação provisória de dificuldade de aprendizagem em Língua Portuguesa e Matemática; e,

VII. em situação de risco nutricional. (BRASIL, 2017, p. 5 e 6)

Além destes grupos, ainda há a possibilidade de participação daqueles que não têm estes perfis, mas possuem o interesse em participar das atividades.

Neste novo documento, os sujeitos que atuarão como coordenadores, articuladores, mediadores e facilitadores também precisam atender a um determinado perfil, a saber:

Tabela 3: Os sujeitos que atuam no Programa Novo Mais Educação

\begin{tabular}{|c|c|}
\hline COORDENADOR & $\begin{array}{l}\text { No âmbito do sistema, é o profissional que se responsabilizará por } \\
\text { acompanhar a implantação do Programa e monitorar sua execução, validando } \\
\text { os relatórios das escolas e elaborando o relatório de atividades do município, } \\
\text { do estado ou do Distrito Federal no Programa Dinheiro Direto na Escola - } \\
\text { PDDE Interativo. } \\
\text { É importante que o coordenador seja um profissional engajado com a } \\
\text { educação integral e com habilidade para realizar avaliação de programas e } \\
\text { projetos. }\end{array}$ \\
\hline ARTICULA & $\begin{array}{l}\text { Deve ser professor, coordenador pedagógico ou possuir cargo equi } \\
\text { com carga horária mínima de } 20 \text { horas, em efetivo exe }\end{array}$ \\
\hline
\end{tabular}




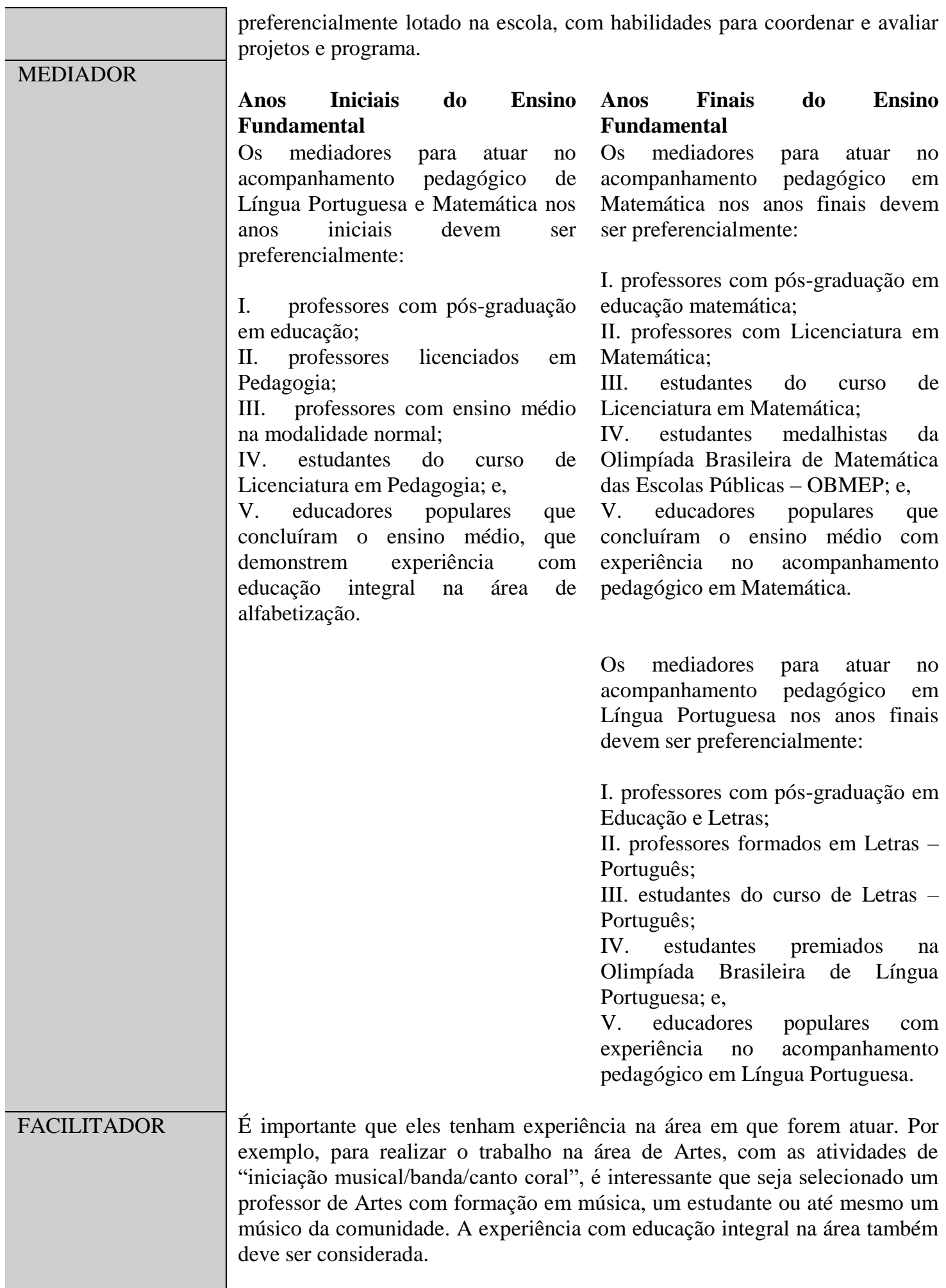

Fonte: Dados organizados pela autora com base em informações do Caderno de Orientações Pedagógicas (BRASIL, 2017).

Surge, no trecho retirado deste documento, a figura do Educador Popular. Neste sentido, analisaremos, no decorrer da pesquisa, se este sujeito pode ser considerado um educador social, segundo os estudos realizados pelo Projeto de Extensão Fora da Sala de Aula, coordenado pelo professor Arthur Vianna Ferreira da UERJ/ FFP, no campo da 
Pedagogia Social. Quem é este sujeito que faz o acompanhamento pedagógico destes campos do saber?

As avaliações farão parte do PNME, por meio dos seguintes instrumentos: "a observação, as fichas de registro, o debate, o portfólio, o conselho de classe, os trabalhos individuais e em grupo, a autoavaliação, a prova em suas diversas variações, entre outros" (BRASIL, 2017). O monitoramento do PNME será realizado via PDDE interativo, com a utilização de relatórios periódicos (BRASIL, 2016). Após implantação deste novo programa, será possível verificar, ao longo dos anos, se o mesmo constituirá (im)possibilidade de indução da ampliação da jornada com vistas ao cumprimento da meta 6 do Plano Nacional de Educação.

A metodologia utilizada nesta investigação será a análise documental, como técnica exploratória, levantamento bibliográfico e questionários estruturados encaminhados para todas as Secretarias Municipais de Educação da região metropolitana do estado do Rio de Janeiro - pesquisa Survey. Na pesquisa bibliográfica que trará à discussão a educação integral $\mathrm{e}(\mathrm{m})$ tempo integral, contaremos inicialmente, com as seguintes referências: Cavaliere (2009), Coelho (2009,), Coelho e Maurício (2016), Menezes (2009), Ribeiro (1986) e Teixeira (2009).

No que tange à gestão democrática, as referências utilizadas, a princípio, estão elencadas a seguir: Amaral (2016), Bernado \& Christovão (2016), Bordenave (1994) Bernado e Silva (2017). Suas contribuições nos levam a discutir sobre a representação e a participação na gestão democrática. Fatores que podem colaborar para a consecução de uma educação de qualidade. No entanto, Silva e Bernado sinalizam que,

Embora a proposta de democratizar o processo no âmbito da gestão avance no sentido da participação mais igualitária entre gestores e professores, deve levar em conta, [...], o regime político e as políticas macros da administração pública com as quais tem que interagir continuamente. (SILVA; BERNADO, 2017, p. 305)

A análise de conteúdo de Bardin (2016) será utilizada para a melhor compreensão dos dados obtidos, favorecendo inferências nos resultados desta pesquisa, que contará, ainda com a análise das seguintes questões:

1- Políticas de educação em tempo integral no âmbito das políticas educacionais nacionais e municipais até a chegada do PNME na região metropolitana do estado do Rio de Janeiro;

2- A gestão democrática e como ela se materializa nos Planos Municipais de Educação e nos espaços escolares. 
3- Como a gestão democrática (im)possibilita o fomento das políticas de educação em tempo integral, tendo em vista a contribuição para a formação mais completa dos sujeitos.

\section{Considerações Finais}

Finalizar este estudo ainda não é possível. Aqui, estão registradas as principais impressões sobre o panorama que se descortina diante de nossos olhos. Em 2016, ano em que acontece o impeachment da presidenta Dilma Rousseff, mudanças significativas acontecem no cenário brasileiro.

O novo Presidente e sua equipe, propõem mudanças no investimento destinado a educação e a saúde, reformulação do currículo do Ensino Médio, reforma trabalhista e na previdência, substituem o Programa Mais Educação (BRASIL, 2007) pelo Programa Novo Mais Educação (BRASIL, 2016a), que, dá ênfase a leitura, escrita e cálculo (BRASIL, 2016b). Quanto a isto, pensamos que outras áreas do conhecimento também colaboram para a formação integral dos sujeitos.

No Estado do Rio de Janeiro há um movimento do governo para privatização da CEDAE, responsável pelo fornecimento de água; precarização da UERJ e atraso no pagamento de servidores. Este panorama sugere a possibilidade de um estado de exceção (AGAMBEN, 2008). Darcy Ribeiro, nos traz sua reflexão sobre momentos como este, quando infere que "a crise educacional do Brasil, da qual tanto se fala, não é uma crise, é um programa. Um programa em curso, cujos frutos, amanhã, falarão por si mesmos" (RIBEIRO, 2013, p. 20)

Muitas questões relacionadas à educação, aos alunos, aos profissionais de educação estão incertas em 2017. No entanto, o Plano Nacional de Educação tem suas metas e seu prazo. E os planos municipais e estaduais, também. Observamos, especificamente na região metropolitana do Estado do Rio de Janeiro que a maioria dos municípios sinaliza o aporte do extinto Programa Mais Educação como fundamental para a consecução da ampliação da jornada nas escolas.

Por conseguinte, questiona-se se o referido programa cumprirá o seu papel de política indutora de ampliação da jornada. E se os municípios poderão caminhar com autonomia. Resta-nos, verificar, portanto, em que medida o Programa Novo Mais Educação favorecerá o alcance da meta 6. Se o programa apresentará avanços em relação aos problemas verificados na implementação do Programa Mais Educação ou se representará retrocessos. E, por fim, de 
que forma a gestão democrática favorece a ampliação da jornada. Esta é uma das propostas dessa pesquisa: trazer à discussão este tema importante para a sociedade brasileira. Como caminhará a educação pública?

\section{REFERÊNCIAS}

AGAMBEN, Giorgio. Estado de exceção. São Paulo: Boitempo, 2004

AMARAL, Daniela Patti do. Gestão democrática: questões sobre a gestão escolar em escolas públicas no Brasil e em Portugal. Revista Trabalho, Política e Sociedade, v. 1, n. 1, p. 77 94, jul./dez., 2016.

BARDIN, Laurence. Análise de conteúdo. São Paulo: Edições 70, 2016.

BERNADO, Elisangela da Silva; CHRISTOVÃO, Ana Carolina. Tempo de Escola e Gestão Democrática: o Programa Mais Educação e o IDEB em busca da qualidade da educação. Revista Educação \& Realidade, Porto Alegre, v. 41, n. 4, p. 1113-1140, out./dez., 2016.

BERNADO, Elisangela da Silva.; SILVA, Tania Mara Tavares da. A relação família e escola: desafios para a gestão escolar. Revista Educação e Cultura Contemporânea, v. 14, n. 34, 2017.

BORDENAVE, Juan E. Díaz. O que é participação. São Paulo: Brasiliense, 1994.

BRASIL. Lei n. 9. 394, de 20 de dezembro de 1996. Estabelece as Diretrizes e Bases da Educação Nacional. Diário Oficial da União. Brasília, DF, v. 134, n. 248, 1996.

BRASIL. Lei nº 8.069, Estatuto da Criança e do Adolescente. Brasília, DF, 1990

BRASIL. Lei no 11.494, Regulamento do Fundo de Manutenção e Desenvolvimento da Educação Básica e de Valorização dos Profissionais da Educação - FUNDEB, de que trata o art. 60 do Ato das Disposições Constitucionais Transitórias. Brasília, DF, 2007.

BRASIL. Lei no 13.005, de 24 de junho de 2014. Aprova o Plano Nacional de Educação. Diário Oficial da União, Brasília, DF, 26 de jun. 2014.

BRASIL. Portaria Interministerial nº ${ }^{\circ}$ 17, de 24 de abril de 2007. Diário Oficial da União, Brasília, DF, 26 abril. 2007.

BRASIL. Portaria nº 1144, de 10 de outubro de 2016. Institui o Programa Novo Mais Educação, que visa melhorar a aprendizagem em língua portuguesa e matemática no ensino fundamental. Diário Oficial da União, Brasília, DF, 11 de out, 2016a

BRASIL. Ministério da Educação. Programa Novo Mais Educação: Documento orientador. Adesão. Versão 1. Brasília, DF: MEC, 2016 b. 
CAVALIERE, Ana Maria. Escolas de tempo integral versus aluno em tempo integral. In: Revista Em Aberto. MAURÍCIO, Lúcia Velloso (Org.), Brasília, DF, v. 22, n. 80, p. 51-83, abr., 2009.

CAVALIERE, Ana Maria. Educação Integral precisa de mais tempo, mais espaços e atividades educacionais de diferentes naturezas. Jornal do professor. Rio de Janeiro, 2015. Disponível em:

<http://portaldoprofessor.mec.gov.br/conteudoJornal.html?idConteudo=3854>. Acesso em: 15 de maio 2017

COELHO, Lígia Martha Coimbra da Costa. História(s) da educação integral. Brasília: Em aberto, v.22, p. 83-96, abr., 2009

COELHO, Lígia Martha Coimbra da Costa.; MAURÍCIO, Lúcia Velloso. Sobre Tempo e Conhecimentos Praticados na Escola de Tempo Integral. Educação \& Realidade, Porto Alegre, v. 41, n. 4, p. 1095-1112, out./dez. 2016

INEP. Instituto Nacional de Estudos e Pesquisas Educacionais Anísio Teixeira, 2014. Disponível em: <http://portal.inep.gov.br/basica-censo〉. Acesso em: 25 de ago. 2016.

MPRJ. Planos Municipais de Educação. Ministério Público Do Estado Do Rio De Janeiro, 2017. Disponível em <http://www.mprj.mp.br/areas-de-atuacao/educacao/controle-social-naeducacao/planos-de-educacao-dos-municipios-do-rio-de-janeiro>. Acesso em: 29 de maio 2017.

MENEZES, Janaína. Educação Integral \& Tempo Integral na Educação Básica. In: COELHO, Lígia Marta C. C. (Org.) Educação integral em tempo integral: estudos e experiências em processo. Petrópolis, RJ: DP et al; Rio de Janeiro, RJ: FAPERJ, 2009

RIBEIRO, Darcy. O Livro dos CIEPs. Rio de Janeiro: Editora Bloch, 1986.

TEIXEIRA, Anísio Spíndola. Educação é um direito. 4. Ed. Rio de Janeiro: Editora UFRJ, 2009

\section{Como referenciar este artigo}

MOTA, Patrícia Flavia. A gestão democrática e a materialização da Meta 6 do Plano Nacional de Educação: possibilidade de educação em tempo integral na região metropolitana do Estado do Rio de Janeiro. Revista on line de Política e Gestão Educacional, Araraquara, v.22, n.1, p. 351-364, jan./abr., 2018 ISSN: 1519-9029. DOI: 10.22633/rpge.v22.n.1.2018.10703

Submetido em: 26/11/2017

Aprovado em: 28/02/2018 